\title{
The curious case of thin-body Ge crystallization
}

\author{
R. Duffy, ${ }^{1, a)}$ M. Shayesteh, ${ }^{1}$ B. McCarthy,${ }_{1}^{1}$ A. Blake, ${ }^{1}$ M. White, ${ }^{1}$ J. Scully, ${ }^{1}$ R. Yu, ${ }^{1}$ \\ A.-M. Kelleher, ${ }^{1}$ M. Schmidt, ${ }^{1}$ N. Petkov, ${ }^{1}$ L. Pelaz, ${ }^{2}$ and L. A. Marqués ${ }^{2}$ \\ ${ }_{1}^{1}$ Tyndall National Institute, University College Cork, Lee Maltings, Cork, Ireland \\ ${ }^{2}$ Universidad de Valladolid, Campus Miguel Delibes, 47011 Valladolid, Spain
}

(Received 17 August 2011; accepted 2 September 2011; published online 29 September 2011)

\begin{abstract}
The authors investigate the templated crystallization of thin-body Ge fin structures with high aspect ratios. Experimental variables include fin thickness and thermal treatments, with fin structures oriented in the $\langle 110\rangle$ direction. Transmission electron microscopy determined that various crystal defects form during crystallization of amorphous Ge regions, most notably $\{111\}$ stacking faults, twin boundaries, and small crystallites. In all cases, the nature of the defects is dependent on the fin thickness and thermal treatments applied. Using a standard $600{ }^{\circ} \mathrm{C}$ rapid-thermal-anneal, $\mathrm{Ge}$ structures with high aspect ratios crystallize with better crystal quality and fewer uncured defects than the equivalent Si case, which is a cause for optimism for thin-film Ge devices. (C) 2011 American Institute of Physics. [doi:10.1063/1.3643160]
\end{abstract}

While Si has dominated the semiconductor industry for many decades, alternative materials such as Ge, III-Vs, and graphene are rapidly emerging as realistic competitors. These materials may be less mature, but a brief literature scan of the recent past clearly shows an increase in popularity in alternative materials, and more importantly real progress in terms of processing and expertise. Ge, in particular, with high carrier mobilities and narrow bandgap, has been seen in applications such as field-effect-transistors, ${ }^{1,2}$ photonics, ${ }^{3}$ nanocrystals, ${ }^{4}$ nanowires, ${ }^{5}$ and solar cells. ${ }^{6}$ Ge has the added advantage of being $\mathrm{Si}$ compatible, and thus it can be processed side-by-side on existing Si platforms and infrastructures. For metal-oxide-semiconductor (MOS) device scaling, a traditional architecture, with planar bulk substrates and highly doped channels for short-channel-effect (SCE) control, is problematic due to excessive leakage currents. ${ }^{7}$ To overcome this, thin-body architectures are being considered which operate in partially depleted, fully depleted, or accumulation mode. ${ }^{8}$ Due to the narrow bandgap of Ge leading to worse diode leakage than in $\mathrm{Si}^{9}{ }^{9}$ it is realistic to assume that if $\mathrm{Ge}$ is to be used in future MOS technologies, it will be in the thin-body form.

Doping thin-body features can be quite a substantial challenge, as it is difficult to get the impurity atoms into the structure, activate them, and prevent them escaping during thermal treatments, while maintaining good crystalline integrity of the semiconductor crystal. ${ }^{10}$ Indeed proposed conformal doping techniques such as plasma or vapor phase doping may evolve as the ultimate choice for multi-gate-field-effecttransistor (MugFET) optimization, while nanowire applications using plasma doping have been reported recently. ${ }^{11,12}$ However, at this point in time ion implant is still the industry standard, and recently Veloso et al. explored several MugFET doping schemes using conventional ion implant for both logic and dense circuits. ${ }^{13}$ A cause for concern for MugFET optimization is the trade-off between parasitic source-drain resistance $\left(\mathrm{R}_{\mathrm{SD}}\right)$ and fin width $\left(\mathrm{W}_{\mathrm{fin}}\right)$. Fins must be narrow to control SCE. High $\mathrm{R}_{\mathrm{SD}}$ and device variability

${ }^{\text {a)} E l e c t r o n i c ~ m a i l: ~ r a y . d u f f y @ t y n d a l l . i e . ~}$ can often be correlated with poor Si crystal quality of previously amorphized thin-body Si regions, ${ }^{14}$ thus having a good recrystallization methodology after implant cannot be underestimated. Moreover, Ge is more likely to amorphize than $\mathrm{Si}^{15}$ as mid- $10^{13} \mathrm{~cm}^{-2} \mathrm{P}$ or As implants will commonly amorphize $\mathrm{Ge}$ at room temperature. As a consequence, it is the aim of this work to study the effect of amorphization and recrystallization in thin-body Ge structures.

High-resistivity $(>40 \Omega \mathrm{cm})$ pre-cleaned (100) Ge wafers were patterned using e-beam lithography and a $\mathrm{SF}_{6} /$ $\mathrm{C}_{4} \mathrm{~F}_{8}$ plasma etch process, resulting in fin arrays of $\mathrm{W}_{\text {fin }}=20-150 \mathrm{~nm}$ and fin height $\left(\mathrm{H}_{\mathrm{fin}}\right)$ of approximately $435 \mathrm{~nm}$. Fins were patterned running in the $\langle 110\rangle$ direction. The test structure consisted of arrays of 10 fins running in parallel. As shown schematically in Figs. 1(a) and 1(c), P was implanted at $7^{\circ}$ with a dose of $1 \times 10^{15} \mathrm{~cm}^{-2}$ and energy of $60 \mathrm{keV}$, which partially amorphized the wide fins and fully amorphized the narrow fins $\left(\mathrm{W}_{\mathrm{fin}}=35 \mathrm{~nm}\right.$ and narrower). For crystallization, some samples received a $400{ }^{\circ} \mathrm{C} 3 \mathrm{~min}$ furnace anneal in $\mathrm{N}_{2}$ and others a $600^{\circ} \mathrm{C} 1 \mathrm{~s}$ rapid-thermalanneal (RTA) in $\mathrm{N}_{2}$. Cross-sectional transmission electron microscopy (XTEM) was carried out using JEOL 2100 HRTEM operated at $200 \mathrm{kV}$. Cross-section samples were obtained by using FEIs Dual Beam Helios Nanolab system. The sample preparation process started with electron beam induced deposition of thin layers of $\mathrm{C}$ and $\mathrm{Pt}$, followed by ion beam induced deposition of a thick Pt protection layer. These were deposited on the region of interest prior to focused ion beam milling. The final Ga-ion polishing of the thin foils was achieved at $10^{\circ}$ off-normal direction at $2 \mathrm{kV}$ with low beam currents in order to remove sub-10 $\mathrm{nm} \mathrm{Ga-ion}$ damage. The XTEM images shown throughout this paper are a representative sample from a larger collection. Figures 1(b) and 1(d) show XTEM images of wide and narrow fins after ion implantation. In some cases, voids are visible between the fins, due to the difficulty of filling between structures of such high aspect ratio during XTEM sample preparation.

Figure 2 shows XTEM images of a $130 \mathrm{~nm}$ wide fin after a recrystallization anneal of $400{ }^{\circ} \mathrm{C} 3 \mathrm{~min}$ in $\mathrm{N}_{2}$. In Fig. 2(a), facet defects are visible at the foot of the structures, similar 


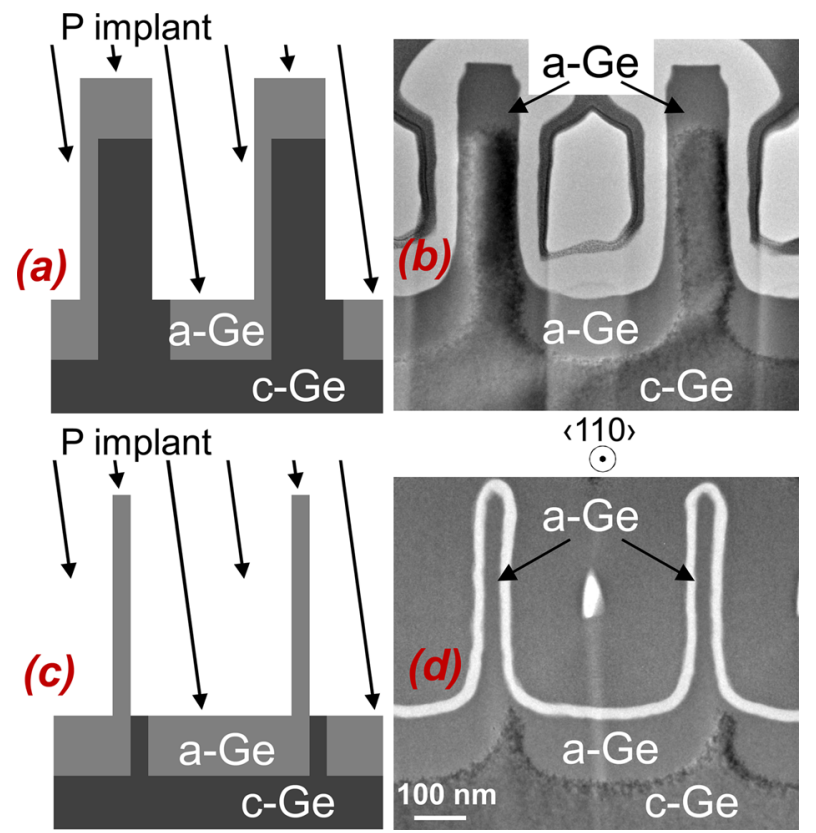

FIG. 1. (Color online) Schematics and XTEM images of wide fins (a) and (b) and of narrow fins (c) and (d). The $7^{\circ} \mathrm{P}$ implant serves to amorphize the top $120 \mathrm{~nm}$ of the wide fins, as well as partly amorphizing the sidewall. The narrow fins ( $35 \mathrm{~nm}$ wide and thinner) are completely amorphized. Fin height is approximately $435 \mathrm{~nm}$.

to those observed in $\mathrm{Si}$ when two crystallization fronts meet. ${ }^{16}$ In the recrystallized portion of the fin, there are a few small defects and $\{111\}$ stacking faults.

Figure 3 shows XTEM analysis of narrow fins (25$30 \mathrm{~nm}$ wide) after a recrystallization anneal of $400{ }^{\circ} \mathrm{C} 3 \mathrm{~min}$ in $\mathrm{N}_{2}$. In Fig. 3(a), a zoomed-out view of 3 fins from an array show statistical differences from fin to fin, but the general trends are the same. It can be seen that the fins have not completely crystallized, even though $400{ }^{\circ} \mathrm{C} 3$ min should regrow approximately $360 \mathrm{~nm}$ of amorphous Ge in a planar sub-

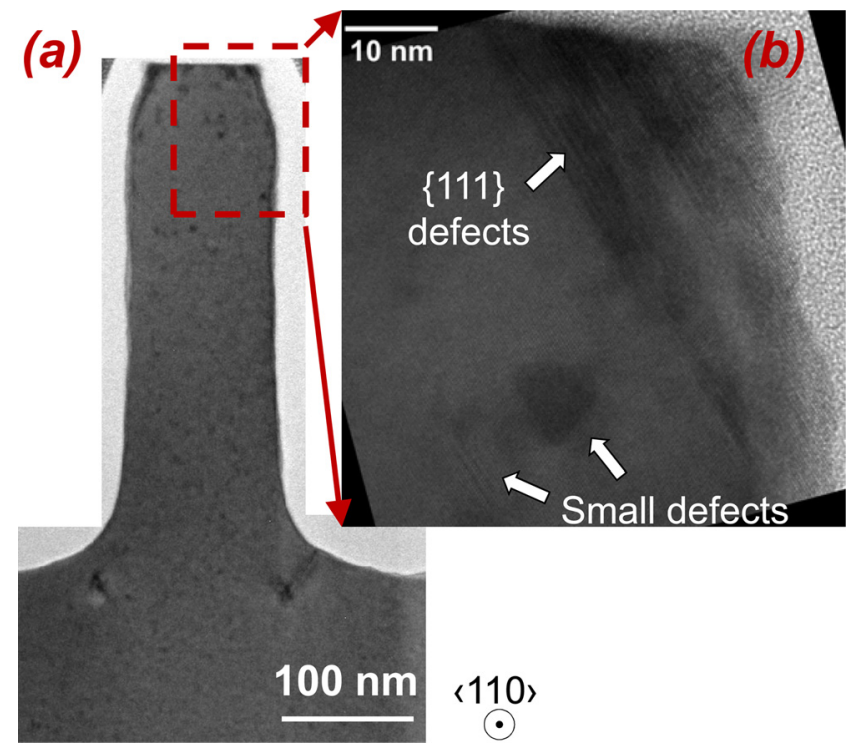

FIG. 2. (Color online) XTEM images of a wide fin after a recrystallization anneal of $400^{\circ} \mathrm{C} 3 \mathrm{~min}$ in $\mathrm{N}_{2}$. (a) There are facet defects at the base of the structure, (b) while the top section shows a few small defects and $\{111\}$ stacking faults.

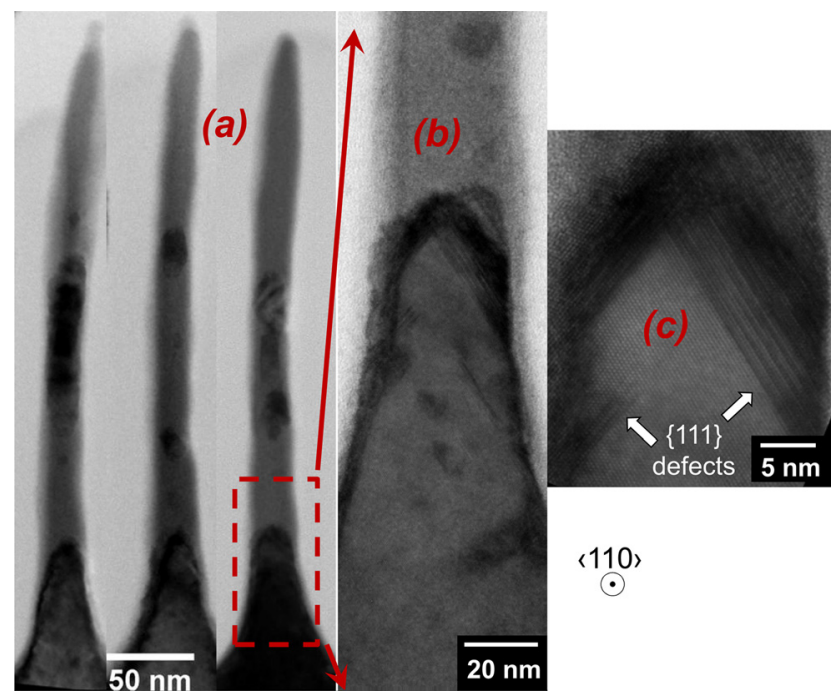

FIG. 3. (Color online) XTEM images of narrow fins after a recrystallization anneal of $400^{\circ} \mathrm{C} 3 \mathrm{~min}$ in $\mathrm{N}_{2}$. (a) Fins have not completely crystallized, (b) in the crystalline Ge region some small defects have survived this anneal, in the amorphous Ge region some small crystallites are present, and (c) an arrowhead-shaped crystallization front accompanied by $\{111\}$ defects are seen at the foot of the fins.

strate ${ }^{17}$ and some crystalline regions can be seen randomly distributed through the amorphized region. Templated crystallization from the base of the structures has been retarded, and as in Si (Ref. 18), it appears regrowth in the $\langle 111\rangle$ direction for Ge is slower than in the $\langle 110\rangle$ or $\langle 100\rangle$ directions. ${ }^{19} \mathrm{~A}$ zoom-in to the crystallization front at the foot a fin is shown in Fig. 3(b). The recently regrown region is not defect-free, as some small defects and portions of $\{111\} \mathrm{s}$ have survived this thermal treatment. Furthermore, some small crystallites can be observed in the amorphous region

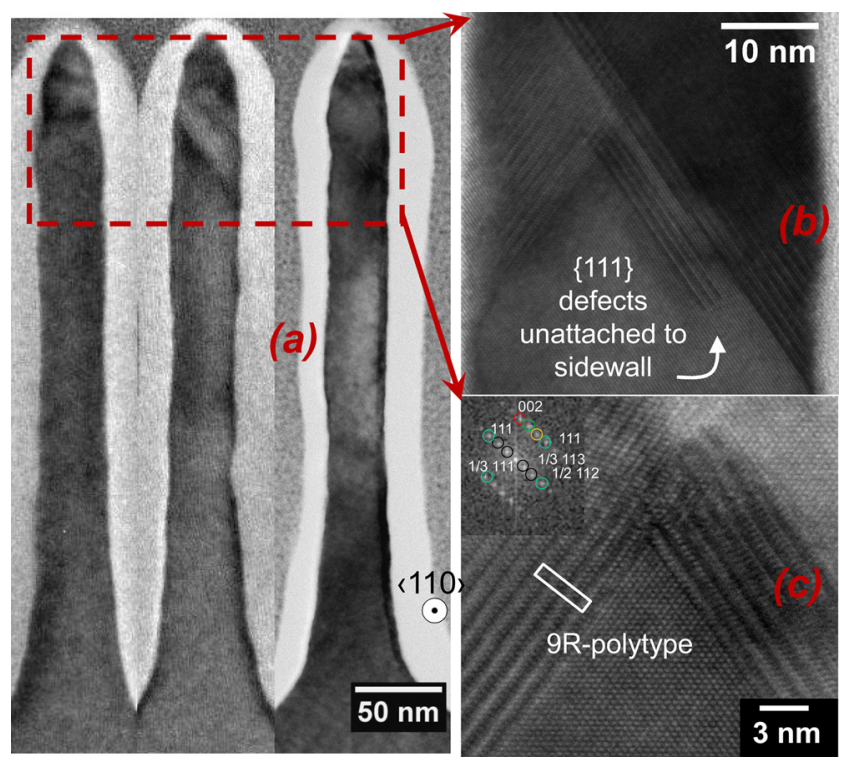

FIG. 4. (Color online) XTEM images of narrow fins after a recrystallization anneal of $600{ }^{\circ} \mathrm{C} 1 \mathrm{~s}$ RTA in $\mathrm{N}_{2}$. (a) Fins have completely crystallized with defects only located in the top of the structures. Defects at the foot and middle of the fins have been cured. (b) $\{111\}$ defects have detached from sidewall, and (c) some sets of stacking faults have ordered themselves in a periodic arrangement forming a different polytype structure. 
ahead of the recrystallization front. In a further zoom-in, in Fig. 3(c), the characteristic arrowhead-shaped front accompanied by $\{111\}$ defects are clearly present at the foot of the fins, as seen previously in the work on Si fins. ${ }^{20}$

The result of a $600^{\circ} \mathrm{C} 1 \mathrm{~s}$ RTA is shown in Fig. 4. Again a zoomed-out view of 3 fins in Fig. 4(a) shows statistical differences from fin to fin, but the general trends are the same. $\mathrm{W}_{\text {fin }}=30-35 \mathrm{~nm}$ in this array. Fins have completely crystallized, with defects only located in the top portion of structures. $\{111\}$ defects at the foot and middle of the fin have been cured. A clue as to how this has happened can be seen in the high-resolution XTEM of Fig. 4(b) where some $\{111\}$ defects have detached from sidewall. It is speculated that the curing of these defects starts at the surfaces and proceeds upwards. Interestingly, we observe that in some regions, the sets of stacking faults along the $\langle 111\rangle$ direction have ordered themselves in a periodic arrangement, forming a different polytype structure. The indexation of such structures can be done based on rhombohedra or hexagonal unit cell as already observed for $\mathrm{Si}$ and $\mathrm{SiC}$. For example, two such regions adopting a rhombohedral $9 \mathrm{R}$ polytype structure combine to form a well defined arrow head structure as shown in Fig. 4(c). Further details on the crystallography and formation mechanism of the Ge polytype structures formed upon thermal recrystallization will be presented in a separate report.

Recrystallization of amorphized Si fins experimentally highlighted the difficulty of templated thin-body semiconductor crystallization. ${ }^{20}$ Twin boundary defects were clearly visible as well as polycrystalline grains. Si crystal quality degraded with decreasing $\mathrm{W}_{\text {fin. }}{ }^{21}$ This has subsequently been modeled by a number of groups using molecular dynamics and lattice kinetic Monte Carlo techniques for $\mathrm{Si}^{22-24}$ and by Posselt and Gabriel using molecular dynamics for $\mathrm{Ge}^{25}$

The formation of these $\{111\}$ defects is an intriguing subject, as they are crystal defects without an excess or deficit of atoms. For an atom to be incorporated in the growing lattice, it should form two undistorted bonds with the crystal. At the sidewall surfaces, the crystal lattice is irregular, and consequently, the formation of undistorted bonds is hindered. \{111\} defects originate the surfaces due to this disturbance of templated atom incorporation into the crystal lattice. Atoms attaching in the $\{111\}$ plane have only one bond with the crystalline phase, and may rotate around that bond axis, causing misorientation. Saenger et al. also did an extensive experimental study in $\mathrm{Si}$ of trench-edge defects along oxide isolation edges for hybrid-orientation substrate applications, ${ }^{26}$ and later it was shown $\langle 110\rangle$ directions on (100) wafers produce $\{111\}$ twins which was resolved by rotating structure in the $\langle 100\rangle$ direction. In that body of work annealing at a very high temperature (e.g., $1325^{\circ} \mathrm{C}$ ) cured defects, ${ }^{27}$ which was also observed in Si by Skibitzki et al. using a $1000^{\circ} \mathrm{C} 60 \mathrm{~s}$ anneal. ${ }^{28}$ Such high thermal budget anneals almost certainly produce significant dopant diffusion. It is noteworthy in this work that a very modest thermal budget $\left(600^{\circ} \mathrm{C} 1 \mathrm{~s}\right.$ RTA) can produce the same curing effect in Ge.

In conclusion, after an RTA treatment, Ge fins with high aspect ratios in the order of 15:1 have almost entirely crystal- lized defect-free from the crystalline template at the foot of the structures. Lower thermal budgets show that $\{111\}$ stacking faults form during the early stages of crystallization, which is similar to that seen in Si. However, while high thermal budgets are required to cure these defects in $\mathrm{Si}$, a $600{ }^{\circ} \mathrm{C} 1 \mathrm{~s}$ anneal in $\mathrm{N}_{2}$ was shown to efficiently clean up the Ge structures studied in this work.

This work has been funded by the Science Foundation Ireland under Research Grant Nos. 09/SIRG/I1623 and 09/SIRG/I1621.

${ }^{1}$ A. Toriumi, T. Tabata, C. H. Lee, T. Nishimura, K. Kita, and K. Nagashio, Microelectron. Eng. 86, 1571 (2009).

${ }^{2}$ F. Bellenger, B. De Jaeger, C. Merckling, M. Houssa, J. Penaud, L. Nyns, E. Vrancken, M. Caymax, M. Meuris, T. Hoffmann, K. De Meyer, and M. M. Heyns, IEEE Electron Device Lett. 31, 402 (2010).

${ }^{3}$ J. Xia, K. Nemoto, Y. Ikegami, N. Usami, Y. Nakata, and Y. Shiraki, Thin Solid Films 517, 125 (2008).

${ }^{4}$ M. Klimenkov, W. Matz, S. A. Nepijko, and M. Lehmann, Nucl. Instrum. Methods Phys. Res. B 179, 209 (2001).

${ }^{5}$ S. Huang, S.-K. Shin, N. Fukata, and K. Ishibashi, J. Appl. Phys. 109, 036101 (2011).

${ }^{6}$ D. Crisp, A. Pathare, and R. C. Ewell, Acta Astronaut. 54, 83 (2003).

${ }^{7}$ R. Duffy, A. Heringa, V. C. Venezia, J. Loo, M. A. Verheijen, M. J. P. Hopstaken, K. van der Tak, M. de Potter, J. C. Hooker, P. Meunier-Beillard, and R. Delhougne, Solid-State Electron. 54, 243 (2010).

${ }^{8}$ FinFETs and Other Multi-Gate Transistors, edited by J. P. Colinge (Springer, New York, 2007).

${ }^{9}$ G. Eneman, M. Wiot, A. Brugère, O. S. I. Casain, S. Sonde, D. P. Brunco, B. De Jaeger, A. Satta, G. Hellings, K. De Meyer, C. Claeys, M. Meuris, M. M. Heyns, and E. Simoen, IEEE Trans. Electron Devices 55, 2287 (2008).

${ }^{10}$ R. Duffy and M. Shayesteh, AIP Conf. Proc. 1321, 17 (2010).

${ }^{11}$ H. Schmid, M. T. Björk, J. Knoch, S. Karg, H. Riel, and W. Riess, Nano Lett. 9, 173 (2009).

${ }^{12}$ E. Tutuc, J. Appenzeller, M. C. Reuter, and S. Guha, Nano Lett. 6, 2070 (2006).

${ }^{13}$ A. Veloso, A. De Keersgieter, S. Brus, N. Horiguchi, P. P. Absil, and T. Hoffmann, Jpn. J. Appl. Phys. 50, 04DC16 (2011).

${ }^{14}$ M. J. H. van Dal, R. Duffy, B. J. Pawlak, N. Collaert, M. Jurczak, and R. J. P. Lander, Mater. Res. Soc. Symp. Proc. 1070, 67 (2008).

${ }^{15}$ T. E. Haynes and O. W. Holland, Appl. Phys. Lett. 61, 61 (1992).

${ }^{16}$ K. L. Saenger, K. E. Fogel, J. A. Ott, D. K. Sadana, and H. Yin, J. Appl. Phys. 101, 104908 (2007).

${ }^{17}$ A. Claverie, S. Koffel, N. Cherkashin, G. Benassayag, and P. Scheiblin, Thin Solid Films 518, 2307 (2010).

${ }^{18}$ L. Csepregi, J. W. Mayer, and T. W. Sigmon, Appl. Phys. Lett. 29, 92 (1976).

${ }^{19}$ L. Csepregi, R. P. Küllen, J. W. Mayer, and T. W. Sigmon, Solid State Commun. 21, 1019 (1977).

${ }^{20}$ R. Duffy, M. J. H. Van Dal, B. J. Pawlak, M. Kaiser, R. G. R. Weemaes, B. Degroote, E. Kunnen, and E. Altamirano, Appl. Phys. Lett. 90, 241912 (2007).

${ }^{21}$ R. Duffy, M. J. H. van Dal, B. J. Pawlak, N. Collaert, L. Witters, R. Rooyackers, M. Kaiser, R. Weemaes, M. Jurczak, and R. Lander, in Proceedings of the European Solid-State Device Research Conference (ESSDERC) (IEEE, Edinburgh, 2008), p. 334.

${ }^{22}$ L. Pelaz, L. Marques, M. Aboy, P. Lopez, I. Santos, and R. Duffy, Tech. Dig. - Int. Electron Devices Meet. 2009, 513.

${ }^{23}$ E. Lampin and C. Krzeminski, J. Appl. Phys. 109, 123509 (2011).

${ }^{24}$ I. Martin-Bragado, Appl. Phys. Lett. 98, 233109 (2011).

${ }^{25}$ M. Posselt and A. Gabriel, Phys. Rev. B 80, 045202 (2009).

${ }^{26}$ K. L. Saenger, J. P. de Souza, K. E. Fogel, J. A. Ott, A. Reznicke, C. Y. Sung, D. K. Sadana, and H. Yin, Appl. Phys. Lett. 87, 221911 (2005).

${ }^{27}$ K. L. Saenger, J. P. de Souza, K. E. Fogel, J. A. Ott, C. Y. Sung, and D. K. Sadana, J. Appl. Phys. 101, 024908 (2007).

${ }^{28}$ O. Skibitzki, Y. Yamamoto, M. A. Schubert, G. Weidner, and B. Tillack, Solid-State Electron. 60, 13 (2011). 